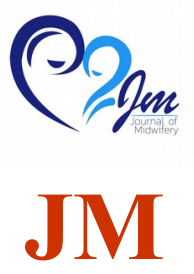

Volume 8 No. 2 (Oktober 2020)

(C) The Author(s) 2020

\title{
HUBUNGAN PENGETAHUAN DAN DUKUNGAN KELUARGA DENGAN PEMBERIAN ASI EKSKLUSIF PADA BAYI USIA 0-6 BULAN DI WILAYAH KERJA PUSKESMAS RATU AGUNG KOTA BENGKULU TAHUN 2015
}

\author{
RELATIONSHIP BETWEEN KNOWLEDGE AND FAMILY SUPPORT WITH \\ EXCLUSIVE BREASTFEEDING AT 0-6 MONTHS OLD BABY IN RATU AGUNG \\ HEALTH CENTER WORKING AREA BENGKULU CITY 2015
}

\author{
JUMITA, SYAMI YULIANTI \\ FAKULTAS ILMU KESEHATAN UNIVERSITAS DEHASEN BENGKULU \\ Email: itajumita78@gmail.com HP: 081368534092
}

\begin{abstract}
ABSTRAK
Air Susu Ibu (ASI) adalah sumber nutrisi terpenting yang dibutuhkan oleh setiap bayi, ASI diberikan secara eksklusif selama 6 bulan pertama kehidupan dan dilanjutkan dengan makanan pendamping sampai usia 2 tahun. Tujuan dari penelitian ini adalah untuk mengetahui hubungan antara pengetahuan dan dukungan keluarga dengan pemberian ASI eksklusif. Jenis penelitian yang dilakukan adalah metode analitik dengan rancangan cross sectional. Sampel dalam penelitian ini sebanyak 128 Ibu yang memiliki bayi usia 7-12 bulan dengan teknik pengambilan sampel secara systematic sampling. Menggunakan data primer dan sekunder yang diolah secara Analisa univariat dan bivariat menggunakan uji statistik Chi-Square. Penelitian dilaksanakan 29 April-27 Mei. Hasil penelitian ini menunjukkan bahwa dari 128 Ibu yang memiliki bayi usia 712 bulan hampir seluruh Ibu (76.6\%) tidak memberikan ASI eksklusif pada bayinya, distribusi frekuensi pengetahuan Ibu mengenai ASI eksklusif sebagian besar memiliki pengetahuan kurang (53.9\%) dan hampir sebagian dukungan keluarga kurang (49.2\%). Hasil analisis bivariat menggunakan uji Chi-Square didapatkan nilai $p=0,000 \leq(0,05)$. Berarti ada hubungan yang bermakna antara pengetahuan dan dukungan keluarga dengan pemberian ASI eksklusif. Petugas kesehatan (Bidan) harus lebih berperan dalam meningkatkan kesadaran masyarakat terhadap pemberian ASI secara eksklusif dengan program yang ada di Puskesmas Ratu Agung Kota Bengkulu.
\end{abstract}

Kata Kunci: Pengetahuan, Dukungan Keluarga, Pemberian ASI

\begin{abstract}
Breast Milk (ASI) is the most important source of nutrients needed by every baby, given exclusively during the first 6 months of life and continued with complementary foods up to 2 years. The purpose of this study was to determine the relationship between knowledge and family support with exclusive breastfeeding. Type of research was an analytic method with
\end{abstract}


cross sectional design. The sample in this study were 128 mothers with babies aged 7-12 months with sampling technique using systematic sampling. Using primary and secondary data are processed in univariate and bivariate analysis using statistical test Chi-Square. The research was conducted at April 29-May 27. The results of this study showed that from 128 Mothers with babies aged 7-12 months almost of them (76.6\%) did not give exclusive breastfeeding for the baby, frequency distribution of mother knowledge about exclusive breastfeeding most have less knowledge $(53.9 \%)$ and almost half have poor families support $(49.2 \%)$. The results of the bivariate analysis using Chi-square test get $\mathrm{p}$ value $=0.000 \leq(0.05)$. Means there was a significant relationship between knowledge and family support with exclusive breastfeeding. Health workers (midwives) should do more to raise public awareness of breastfeeding exclusively with existing programs in Ratu Agung Health Center Bengkulu.

\section{Keywords: Awareness, Family Support, Breastfeeding}

\section{PENDAHULUAN}

Air Susu Ibu (ASI) adalah sumber nutrisi terpenting yang dibutuhkan oleh setiap bayi. ASI diberikan secara eksklusif selama 6 bulan pertama kehidupan dan dilanjutkan dengan makanan pendamping sampai usia 2 tahun. Riset World Health Organization (WHO) pada tahun 2010 menyebutkan bahwa 42\% kematian balita di dunia adalah penyakit pneumonia dan sebanyak 58\% terkait dengan malnutrisi. Malnutrisi seringkali terkait dengan kurangnya asupan ASI dan pemberian Makanan Pendamping ASI (MP-ASI) secara dini (Damandiri, 2010). Hasil survei Riskesdas 2013 (Riset Survei Kesehatan Dasar) yang dilakukan oleh Kementerian Kesehatan Indonesia, penderita gizi buruk di Indonesia selama periode tahun 2007-2013 mengalami peningkatan yaitu dari $5,4 \%$ menjadi 5,7\% (Welfare Indicators, 2014).

Menurut WHO dan UNICEF (2012) laporan anak dunia 2011 yaitu dari 136,7 juta bayi lahir di seluruh dunia dan hanya $32,6 \%$ dari mereka yang disusui secara eksklusif dalam 6 bulan pertama. Menurut Ditjen Gizi dan KIA Kemenkes RI (2014) Cakupan ASI Eksklusif di Indonesia juga mencapai angka yang diharapkan, di mana persentase pemberian ASI eksklusif pada bayi 0-6 bulan di Indonesia pada tahun 2013 sebesar 54,3\% sedikit meningkat bila dibandingkan dengan tahun 2012 yang sebesar 48,6\%. Bengkulu berada di urutan ke 10 dalam pemberian ASI Eksklusif dengan jumlah persentase 50,76\$.
Hal ini menunjukkan masih rendahnya cakupan pemberian ASI eksklusif di Provinsi Bengkulu bila dibandingkan dengan Provinsi lain yang ada di Indonesia (Profil Kesehatan Indonesia, 2013).

ASI selain mengandung gizi yang cukup lengkap, mengandung imun untuk kekebalan tubuh bayi. Keunggulan lainnya ASI disesuaikan dengan sistem pencernaan bayi sehingga zat gizi cepat terserap, berbeda dengan susu formula atau makanan tambahan yang diberikan secara dini pada bayi (Meutia, 2008). ASI mengandung banyak sekali DHA dan zat kebal yang dapat mencegah infeksi atau penyakit pada bayi. Perkembangan otak bayi akan semakin baik apabila bayi semakin banyak meminum ASI (Anggorowati, 2011).

Faktor-faktor yang mempengaruhi ibu dalam memberikan ASI, antara lain faktor sosial budaya, faktor psikologis, faktor fisik $\mathrm{ibu}$, faktor petugas kesehatan, meningkatnya promosi susu formula sebagai pengganti ASI, adanya perubahan struktur masyarakat dan keluarga, iklan tentang makanan bayi yang menyebutkan bahwa makanan bayi lebih baik daripada ASI, ibu yang bekerja, ibu yang beranggapan bentuk payudara akan rusak apabila menyusui dan kecantikannya akan hilang (Meutia, 2008).

Selain itu, kendala ibu dalam menyusui ada dua faktor, pertama faktor internal yaitu kurangnya pengetahuan ibu tentang manajemen laktasi, kedua faktor eksternal yaitu ASI belum keluar pada hari-hari pertama sehingga ibu berfikir perlu tambah 
susu formula, ketidakmengertian ibu tentang kolostrum dan banyak ibu yang masih beranggapan bahwa ASI ibu kurang gizi dan kualitasnya tidak baik (Wowor, M. 2013). Salah satu faktor penting yang juga mempengaruhi ibu dalam pemberian ASI eksklusif adalah dukungan keluarga, di mana seorang ibu yang punya pikiran positif tentu saja akan senang melihat bayinya, kemudian memikirkannya dengan penuh kasih sayang, terlebih jika sudah mencium dan menimang si buah hati. Semua itu terjadi bila ibu dalam keadaan tentang. Keadaan ini didapat oleh ibu jika adanya dukungan-dukungan dari lingkungan sekitar ibu untuk memberikan ASI pada bayinya. Karena itu ibu memerlukan dukungan yang kuat agar dapat memberikan ASI eksklusif. Dukungan ini didapat ibu dari tiga pihak yakni suami, keluarga dan tenaga kesehatan (Hargi, 2013).

Berdasarkan data Profil Dinas Kesehatan Kota Bengkulu tahun 2014 cakupan pemberian ASI eksklusif tahun 2013 sebesar $78,7 \%$ dan tahun 2014 yaitu $81,3 \%$. Berdasarkan data tersebut pencapaian cakupan pemberian ASI eksklusif di Kota Bengkulu menunjukkan peningkatan persentase namun cakupan pemberian Eksklusif terendah pada tahun 2014 adalah $64,0 \%$ mengalami penurunan bila dibandingkan dengan tahun 2013 yaitu $69,0 \%$. Capaian cakupan pemberian ASI eksklusif pada tahun 2014 adalah yang terendah di Kota Bengkulu sebesar 64,0\%. Ini menunjukkan tren penurunan dan masih rendah dari target cakupan ASI eksklusif, dimana pada tahun 2013 cakupan pemberian ASI eksklusif di Puskesmas Ratu Agung yaitu 84,5\% dan 2012 cakupan ASI eksklusif di Puskesmas Ratu Agung sebesar 65,7\%.

Berdasarkan uraian latar belakang di atas penulis tertarik untuk meneliti tentang "Hubungan pengetahuan dan dukungan keluarga dengan pemberian ASI Eksklusif pada bayi usia 0-6 bulan di Wilayah Kerja Puskesmas Ratu Agung Kota Bengkulu tahun 2015".

\section{METODE PENELITIAN}

Jenis penelitian yang digunakan pada penelitian ini adalah metode analitik dengan rancangan cross sectional. Populasi dalam penelitian ini adalah seluruh ibu yang mempunyai bayi usia 7-12 bulan di Wilayah Kerja Puskesmas Ratu Agung Kota Bengkulu dari bulan Januari-Maret 2015 berjumlah 189 bayi. Sampel dalam penelitian ini adalah 128 ibu yang memiliki bayi usia 7-12 bulan dengan teknik pengambilan sampel secara systematic sampling. Alat ukur yang digunakan dalam pengumpulan data pada penelitian ini adalah menggunakan kuesioner dan check list. Penelitian ini dilaksanakan pada tanggal 01 April - 06 Mei 2015 di Wilayah Kerja Puskesmas Ratu Agung Kota Bengkulu.

Metode pengumpulan data pada penelitian ini dilakukan dengan pengambilan data primer dan data sekunder. data primer adalah data yang diperoleh langsung dari responden, sedangkan data sekunder adalah data yang didapatkan dari Puskesmas Ratu Agung. Analisa data menggunakan analisa Univariat dan Bivariat.

\section{HASIL PENELITIAN}

\section{Analisa Univariat}

Tabel 1. Distribusi Frekuensi Pemberian ASI Eksklusif di Wilayah Kerja Puskesmas Ratu Agung Kota Bengkulu

\begin{tabular}{cccc}
\hline No & $\begin{array}{c}\text { Pemberian } \\
\text { ASI Eksklusif }\end{array}$ & Frekuensi & $\begin{array}{c}\text { Persentase } \\
(\mathbf{\%})\end{array}$ \\
\hline 1. & Tidak ASI Eksklusif & 93 & 72.7 \\
\hline 2. & ASI Eksklusif & 35 & 27.3 \\
\hline & Jumlah & 128 & 100 \\
\hline
\end{tabular}

Dari tabel 1 dapat diketahui bahwa hampir seluruh responden $(72.7 \%)$ tidak memberikan ASI eksklusif pada bayinya.

Tabel 2. Distribusi Frekuensi Pengetahuan Ibu di Wilayah Kerja Puskesmas Ratu Agung Kota Bengkulu 


\begin{tabular}{cccc}
\hline No & Pengetahuan Ibu & Frekuensi & $\begin{array}{c}\text { Persentase } \\
(\mathbf{\%})\end{array}$ \\
\hline 1. & Baik & 20 & 15.6 \\
\hline 2. & Cukup & 39 & 30.5 \\
\hline 3. & Kurang & 69 & 53.9 \\
\hline & Jumlah & 128 & 100 \\
\hline
\end{tabular}

Dari tabel 2 dapat diketahui bahwa sebagian besar responden $(53.9 \%)$ memiliki pengetahuan kurang tentang ASI eksklusif.

Tabel 3. Distribusi Frekuensi Dukungan Keluarga di Wilayah Kerja Puskesmas Ratu Agung Kota Bengkulu

\begin{tabular}{cccc}
\hline No & Pengetahuan Ibu & Frekuensi & Persentase (\%) \\
\hline 1. & Baik & 28 & 21.9 \\
\hline 2. & Cukup & 37 & 28.9 \\
\hline 3. & Kurang & 63 & 49.2 \\
\hline & Jumlah & 128 & 100 \\
\hline
\end{tabular}

Dari tabel 3 dapat diketahui bahwa hampir sebagian responden $(49.2 \%)$ memiliki dukungan yang kurang.

\section{Analisa Bivariat}

Tabel 4. Analisis Hubungan Pengetahuan Ibu dengan Pemberian ASI Eksklusif pada Bayi umur 0-6 Bulan di Wilayah Kerja Puskesmas Ratu Agung Kota Bengkulu

\begin{tabular}{cccc}
\hline \multirow{2}{*}{ Pengetahuan } & \multicolumn{2}{c}{ Pemberian ASI } & \multirow{2}{*}{ r } \\
\cline { 2 - 3 } & $\begin{array}{c}\text { Tidak ASI } \\
\text { Eksklusif }\end{array}$ & ASI Eksklusif & \\
\hline Baik & 7 & 13 & \\
& $35 \%$ & $65 \%$ & \\
\hline Cukup & 26 & 13 & \multirow{2}{*}{0.000} \\
& $66.7 \%$ & $33.3 \%$ & \\
\hline Kurang & 60 & 9 & \\
& $87 \%$ & $13 \%$ & \\
\hline Jumlah & 93 & 35 & \\
& $72.7 \%$ & $27.3 \%$ & \\
\hline
\end{tabular}

Berdasarkan tabel 4 dapat diketahui bahwa dari 69 ibu yang memiliki pengetahuan kurang, 87\% tidak memberikan ASI eksklusif. Dari 39 ibu dengan pengetahuan cukup, $66.7 \%$ tidak memberikan
ASI eksklusif. Dari 20 ibu dengan pengetahuan baik, $35 \%$ yang tidak memberikan ASI eksklusif.

Hasil analisis dengan chi-square diketahui nilai $\mathrm{p}=0.000, \mathrm{a} \leq 0.05$, berarti ada hubungan yang bermakna antara pengetahuan dengan pemberian ASI eksklusif di Wilayah Kerja Puskesmas Ratu Agung Kota Bengkulu tahun 2015

Tabel 5. Analisis Hubungan Dukungan Keluarga dengan Pemberian ASI Eksklusif pada Bayi umur 0-6 Bulan di Wilayah Kerja Puskesmas Ratu Agung Kota Bengkulu

\begin{tabular}{|c|c|c|c|}
\hline \multirow{2}{*}{$\begin{array}{c}\text { Dukungan } \\
\text { Keluarga }\end{array}$} & \multicolumn{2}{|c|}{ Pemberian ASI } & \multirow[b]{2}{*}{$\mathbf{r}$} \\
\hline & $\begin{array}{l}\text { Tidak ASI } \\
\text { Eksklusif }\end{array}$ & ASI Eksklusif & \\
\hline Baik & $\begin{array}{c}10 \\
35.7 \%\end{array}$ & $\begin{array}{c}18 \\
64.3 \%\end{array}$ & \multirow{4}{*}{0.000} \\
\hline Cukup & $\begin{array}{c}28 \\
75.7 \%\end{array}$ & $\begin{array}{c}9 \\
24.3 \%\end{array}$ & \\
\hline Kurang & $\begin{array}{c}56 \\
88.9 \%\end{array}$ & $\begin{array}{c}7 \\
11.1 \%\end{array}$ & \\
\hline Jumlah & $\begin{array}{c}98 \\
76.6 \%\end{array}$ & $\begin{array}{c}30 \\
23.4 \%\end{array}$ & \\
\hline
\end{tabular}

Berdasarkan tabel 5 dapat diketahui bahwa dari 63 ibu yang memiliki dukungan kurang, 88.9 tidak memberikan ASI eksklusif. Dari 37 ibu dengan dukungan cukup, 75.7\% tidak memberikan ASI eksklusif. Dari $28 \mathrm{ibu}$ dengan dukungan baik, $24.3 \%$ tidak memberikan ASI eksklusif

Hasil analisis dengan chi-square diketahui nilai $\mathrm{p}=0.000, \mathrm{a} \leq 0.05$, berarti ada hubungan yang bermakna antara dukungan keluarga dengan pemberian ASI eksklusif di Wilayah Kerja Puskesmas Ratu Agung Kota Bengkulu tahun 2015

\section{PEMBAHASAN}

Distribusi Frekuensi Pengetahuan ibu tentang Pemberian ASI eksklusif di Wilayah Kerja Puskesmas Ratu Agung Kota Bengkulu Tahun 2015

Berdasarkan tabel 2 dari 128 responden 
dapat diketahui bahwa sebagian besar responden $(53.9 \%)$ memiliki pengetahuan kurang tentang ASI eksklusif. Penelitian ini sejalan dengan penelitian yang dilakukan oleh Pratiwi yang mendapatkan jumlah responden terbanyak adalah responden dengan tingkat pengetahuan kurang yakni (39.1\%) (Yulianti F, 2014).

Pada penelitian ini masih minimnya pengetahuan Ibu mengenai ASI eksklusif terutama pengertian ASI eksklusif, manfaat ASI eksklusif dan pengetahuan Ibu tentang makanan tambahan pada bayi usia kurang dari 6 bulan. Hal ini tentu ada hal yang mempengaruhinya dimana lingkungan tempat penelitian sangat dipengaruhi oleh budaya yang masih dipakai secara turun-menurun. Serta Ibu-Ibu yang berada di tempat penelitian rata-rata berpendidikan SMP sehingga pengetahuanya tidak seluas yang berpendidikan lebih tinggi.

Hal ini sejalan dengan pendapat Notoatmodjo (2003) mengatakan bahwa pendidikan seseorang berhubungan dengan kehidupan sosialnya. Semakin tinggi pendidikan seseorang maka ia akan memperhatikan masalah kesehatanya. Kemudian diperkuat oleh Wowor M (2013) Ibu dengan pendidikan tinggi akan cenderung memiliki pengetahuan yang baik tentang ASI eksklusif dan sebaliknya Ibu yang memiliki pendidikan rendah cenderung sulit untuk menyerap informasi khususnya pengetahuan tentang ASI eksklusif sehingga menyebabkan sikap tidak peduli terhadap program kesehatan.

Distribusi Frekuensi Dukungan Keluarga dengan Pemberian ASI eksklusif di Wilayah Kerja Puskesmas Ratu Agung Kota Bengkulu tahun 2015

Berdasarkan tabel 3 dari 128 responden dapat diketahui bahwa hampir sebagian (49.2\%) memiliki dukungan yang kurang. Penelitian ini sejalan dengan penelitian Abidjulu FR (2014) yang menunjukkan bahwa dukungan suami dengan pemberian ASI eksklusif termasuk kategori kurang
(54.1\%).

Dalam penelitian ini dukungan pemberian ASI eksklusif pada Ibu hampir sebagian berada pada kategori kurang. Hal ini dikarenakan kurangnya pengetahuan yang didapatkan oleh Ibu mengenai ASI eksklusif, kurangnya dukungan suami dan keluarga serta faktor budaya yang dimiliki oleh Ibu contohnya Ibu lebih memilih memberikan susu formula, madu, air putih dan pisang dibandingkan dengan memberikan ASI eksklusif sebelum bayi berumur lebih dari 6 bulan.

Menurut Roesli (2007), dukungan keluarga merupakan faktor eksternal yang paling besar pengaruhnya terhadap keberhasilan ASI eksklusif. Adanya dukungan keluarga terutama suami maka akan berdampak pada peningkatan rasa percaya diri atau motivasi dari Ibu dalam menyusui. Suririnah (2009), mengatakan bahwa motivasi seorang Ibu sangat menentukan dalam pemberian ASI eksklusif selama 6 bulan. Disebutkan bahwa dorongan dan dukungan keluarga menjadi penentu timbulnya motivasi Ibu dalam menyusui.

\section{Distribusi Frekuensi Pemberian ASI eksklusif di Wilayah Kerja Puskesmas Ratu Agung Kota Bengkulu Tahun 2015}

Berdasarkan tabel 1 dapat diketahui bahwa hampir seluruh responden $(72.7 \%)$ tidak memberikan ASI eksklusif pada bayinya. Hasil penelitian ini sejalan dengan penelitian yang dilakukan oleh Pawenrusi yang mendapatkan hasil bahwa sebagian responden tidak memberikan ASI eksklusif yaitu (62.8\%) (Yulianti F, 2014).

ASI eksklusif adalah pemberian air susu Ibu selama 6 bulan tanpa di campur dengan tambahan cairan lain seperti susu formula, jeruk, madu, air teh, air putih dan tanpa tambahan makanan padat seperti pisang, pepaya, bubur susu, biskuit, dan bubur nasi tim (Maryunani, 2009).

Faktor-faktor yang mempengaruhi Ibu dalam memberikan ASI eksklusif, antara lain adanya perubahan sosial budaya, faktor 
psikologis, faktor fisik Ibu, tenaga kesehatan dan promosi susu formula sebagai pengganti ASI. Selain itu juga dapat disebabkan kurangnya motif dan motivasi Ibu dalam memberikan ASI secara eksklusif (Hamidah N, 2007).

\section{Hubungan Pengetahuan dengan Pemberian ASI eksklusif di Wilayah Kerja Puskesmas Ratu Agung Kota Bengkulu Tahun 2015.}

Berdasarkan tabel 4 di atas menyatakan bahwa dari 128 responden, terdapat $69 \mathrm{Ibu}$ memiliki pengetahuan kurang, (87\%) tidak memberikan ASI eksklusif. 39 Ibu dengan pengetahuan cukup, $(66.7 \%)$ tidak memberikan ASI eksklusif. Dan 20 Ibu dengan pengetahuan baik terdapat (30\%) yang tidak memberikan ASI eksklusif. Hasil analisis dengan chi-square diketahui nilai $\mathrm{p}=$ 0.000 , a $\leq 0.05$, berarti ada hubungan yang bermakna antara pengetahuan dengan pemberian ASI eksklusif.

Penelitian ini sejalan dengan penelitian yang dilakukan oleh Ginting yang mendapatkan nilai $\mathrm{p}$ sebesar 0.001 yang menunjukkan bahwa terdapat hubungan antara tingkat pengetahuan responden dengan pemberian ASI eksklusif. Hasil penelitian yang dilakukan oleh Hilala juga mendapatkan bahwa tingkat pengetahuan responden mengenai ASI eksklusif memiliki hubungan yang signifikan dengan pemberian ASI eksklusif $(\mathrm{p}=0.000)$.

Dari 20 responden terdapat 6 Ibu memiliki pengetahuan baik tetapi tidak memberikan ASI eksklusif pada bayinya. Hal ini dipengaruhi oleh budaya di wilayah setempat yang dipakai secara turun temurun, dimana Ibu masih percaya bahwa pemberian madu, air putih dan susu formula itu lebih bagus daripada ASI.

Pengetahuan adalah hasil dari tahu seseorang yang dilihat dari cara menjawab responden baik benar atau salah terhadap jumlah soal dengan materi pengertian ASI eksklusif, manfaat ASI eksklusif, kandungan yang terdapat di ASI serta waktu yang baik untuk pemberian ASI. Tingkat pengetahuan responden ini diukur melalui daftar pertanyaan/ kuisioner yang diberikan.

Menurut Notoatmodjo (2010) informasi yang didapat seseorang terkait pemberian ASI eksklusif dapat mempengaruhi perilaku orang tersebut dalam memberikan ASI eksklusif. Pengalaman dan penelitian membuktikan bahwa perilaku yang didasari oleh pengetahuan akan lebih langgeng daripada perilaku yang tidak didasari oleh pengetahuan.

\section{Hubungan Dukungan Keluarga dengan Pemberian ASI eksklusif di Wilayah Kerja Puskesmas Ratu Agung Kota Bengkulu Tahun 2015}

Berdasarkan tabel 5 di atas menyatakan bahwa dari 128 responden, terdapat $63 \mathrm{Ibu}$ yang memiliki dukungan kurang, (88.9\%) tidak memberikan ASI eksklusif. 37 Ibu dengan dukungan cukup, (75.7\%) tidak memberikan ASI eksklusif. Dan 28 Ibu dengan dukungan baik, (35.7\%) yang tidak memberikan ASI eksklusif. Hasil analisis dengan chi-square diketahui nilai $\mathrm{p}=0.000$, a $<0.05$, berarti ada hubungan yang bermakna antara dukungan keluarga dengan pemberian ASI eksklusif.

Penelitian ini sejalan dengan penelitian yang dilakukan oleh Wowor (2013) yang mendapatkan nilai $\mathrm{p}$ sebesar $0.036<0.05$ yang menunjukkan bahwa ada hubungan antara dukungan keluarga dengan pemberian ASI eksklusif. Dan dari penelitian sebelumnya yang dilakukan Widiyanto.S (2011) menyatakan bahwa banyak Ibu yang kurang mendukung pemberian ASI eksklusif, hal ini disebabkan karena pengaruh dari lingkungan sekitar. Dimana lingkungan sekitar sangat mempengaruhi seseorang untuk mengambil keputusan yang terbaik. Karena pada zaman modern sekarang ini semakin banyak promosi susu formula yang dianggap praktis oleh Ibu-Ibu.

Dari 28 responden, terdapat 9 Ibu memiliki dukungan keluarga baik tetapi tidak memberikan ASI eksklusif pada bayinya. Hal 
ini dikarenakan pengaruh dari lingkungan yang ada di wilayah setempat, dimana sosial budaya yang ada di wilayah kerja Puskesmas Ratu Agung Kota Bengkulu masih kental.

Dalam penelitian ini dukungan pemberian ASI eksklusif pada Ibu hampir sebagian berada pada kategori kurang. Hal ini dikarenakan kurangnya pengetahuan yang didapatkan oleh Ibu mengenai ASI eksklusif, kurangnya dukungan suami dan keluarga serta faktor kebudayaan dan tradisi yang dimiliki oleh Ibu contohnya Ibu lebih memilih memberikan susu formula, madu, air putih dan pisang dibandingkan dengan memberikan ASI eksklusif sebelum bayi berumur lebih dari 6 bulan. Mereka yakin bahwa makanan tersebut dapat membuat bayi cepat kenyang. Hal ini juga berhubungan dengan dukungan suami dan keluarga dimana menurut budaya bahwa suami adalah kepala keluarga, pengambil kebijakan keluarga sedangkan anggota keluarga yang lain menghendaki untuk mempertahankan budaya yang dianutnya.

Penelitian ini sejalan dengan pendapat Hargi J (2013) yang menyatakan bahwa faktor-faktor yang mempengaruhi pemberian ASI eksklusif adalah pengetahuan Ibu, motivasi Ibu, Kampanye ASI eksklusif, fasilitas pelayanan kesehatan, peranan petugas kesehatan, peranan pertolongan persalinan, peranan atau dukungan keluarga, kebiasaan yang keliru, promosi susu formula, kesehatan Ibu dan anak dan pekerjaan Ibu. Menurut Hamidah N (2007), faktor- faktor yang mempengaruhi Ibu dalam memberikan ASI eksklusif yaitu adanya perubahan sosial budaya, faktor psikologis, faktor fisik Ibu, tenaga kesehatan dan promosi susu formula sebagai pengganti ASI. Selain itu faktorfaktor yang mempengaruhi keberhasilan menyusui adalah dukungan dari keluarga, ketentraman jiwa dan cara menyusui yang benar.

\section{KESIMPULAN}

Berdasarkan hasil penelitian yang dilakukan di Wilayah Kerja Puskesmas Ratu
Agung Kota Bengkulu Tahun 2015, maka dapat disimpulkan sebagai berikut:

1. Hampir seluruh Ibu (72.7\%) yang memiliki bayi usia 7-12 bulan di Wilayah Kerja Puskesmas Ratu Agung Bengkulu tidak memberikan ASI eksklusif pada bayinya.

2. Sebagian besar Ibu (53.9\%) yang memiliki bayi usia 7-12 bulan di Wilayah Kerja Puskesmas Ratu Agung Bengkulu memiliki pengetahuan kurang tentang ASI eksklusif.

3. Hampir sebagian Ibu (49.2\%) yang memiliki bayi usia 7-12 bulan di Wilayah Kerja Puskesmas Ratu Agung Bengkulu memiliki dukungan yang kurang.

4. Ada hubungan yang bermakna antara Pengetahuan dengan Pemberian ASI eksklusif pada Ibu yang memiliki bayi usia 7-12 bulan di Wilayah Kerja Puskesmas Ratu Agung Kota Bengkulu yaitu $\mathrm{p} 0,000<0,05$.

5. Ada hubungan yang bermakna antara Dukungan Keluarga dengan Pemberian ASI eksklusif pada Ibu yang memiliki bayi usia 7-12 bulan di Wilayah Kerja Puskesmas Ratu Agung Kota Bengkulu yaitu p $0,000<0,05$.

\section{SARAN}

1. Bagi Puskesmas Ratu Agung Bengkulu

Diharapkan bagi petugas puskesmas (Bidan) agar lebih meningkatkan kesadaran masyarakat terhadap pemberian ASI secara eksklusif selama 6 bulan dengan program yang ada di puskesmas.

\section{Bagi Peneliti Selanjutnya}

Diharapkan hasil penelitian ini sebagai bahan acuan atau data dasar untuk peneliti selanjutnya dengan variabel yang lain dengan analisis yang lebih tinggi seperti analisis multivariat. 


\section{DAFTAR PUSTAKA}

Abidjulu, FR, Hutagaol E \& Kundre R. (2014). Hubungan Dukungan Suami dengan Kemauan Ibu Memberikan ASI Ekslusif di Puskesmas Tuminting Kecamatan Tuminting. (diakses 02 April 2015).

Anggorowati \& nuzulia, F (2011). Hubungan Antara Dukungan Keluarga denganPemberian ASI Ekslusif pada Bayi di Desa Bebengan Kecamatan Boja Kabupaten Kendal. Kendal

Damandiri, (2010). ASI Ekslusif. (Diakses 21 Maret 2015), diunduh dari http://eprints.undip.ac.id/32661/1/sartini_ 1.pdf

Dinas Kesehatan Provinsi Bengkulu, 2014. Profil Kesehatan Provinsi Bengkulu Tahun 2013. Dinkes Provinsi Bengkulu. Bengkulu

Dinas Kesehatan Kota Bengkulu, 2014. Profil Kesehatan Kota Bengkulu Tahun 2014. Dinkes Kota Bengkulu. Bengkulu

Hamidah, N \& Kusbiantoro, D. (2009). Hubungan Pengetahuan Ibu dengan Pemberian ASI Ekslusif di BPS Yuliana Lamongan, (diakses 01 April 2015). diunduh dari http://uppm.stikesmuhamadiyahlamongan .ac.id

Hargi J. (2013). Skripsi Hubungan Dukungan Suami Dengan Sikap Ibu Dalam Pemberian ASI ekslusif di Wilayah Kerja Puskesmas Arjasa Kabupaten Jember, (diakses 01 April 2015), diunduh dari http://repository.

unej.ac.id/bitstream/handle/123456789/32

19/Jayanta\%20Permana \%20Hargi\%2020072310101008.pdf? sequencer

Maryunani, A. (2009). Asuhan Pada Ibu Dalam Masa Nifas (Postpartum). Jakarta. Trans Info Medika

Meutia. (2008). 86\% Bayi di Indonesia Tidak diberi Asi Ekslusif. http://www. Indonesia .go.id/index

Roesli, U.(2007). Mengenal ASI Ekslusif. Jakarta Trubus Agrudaya

Suririnah.(2009). Buku PintarMerawat Bayi
0-12 Bulan;Panduan Bagi Ibu Baru untuk Menjalani Hari-hari Bahagia dan Menyenangkan bersama bayinya. Jakarta: Gramedia. Pustaka Utama

UNICEF.2011. Breastfeeding. $\mathrm{httD}: / / w w w . u n i c e f . o r g /$ nutrition/index 248 24.html (diakses pada 20 April 2015) diunduh pada 20 April 2015

Widiyanto, S. DKK. (2011). Hubungan Pendidikan dan Pengetahuan Ibu tentang ASI Ekslusif dengan Sikap terhadap Pemberian ASI Ekslusif.

Wowor, M, Loah, M, Pangemanan. (2013). Hubungan Pengetahuan Dan Sikap Dengan Pemberian ASI Ekslusif Pada Ibu Menyusui Di Puskesmas Bahu Kota Manado, Skripsi Fakultas Kedokteran Universitas Sam Ratulangi Manado

Yulianti, F. Fitriangga, A. Nawangsari. (2014). Hubungan Antara Karakteristik, Tingkat Pengetahuan Dan Dukungan Keluarga Terhadap Pemberian ASI Ekslusif Di Wilayah Kerja Puskesmas Siantan Hulu Kecamatan Pontianak Utara Tahun 2014. Naskah Publikasi Program Studi Pendidikan Dokter Fakultas Kedokteran Universitas Tanjungpura Pontianak 